Proceedings of the 33rd Annual Scientific Meeting of the European Embryo Transfer Association (AETE); Bath, United Kingdom, September 8th and 9th, 2017.

\title{
COST-Action GEMINI and EPICONCEPT: what we learned after 8 years?
}

\author{
Ann Van Soom ${ }^{1,4}$, Alireza Fazeli ${ }^{2,3}$ \\ ${ }^{1}$ Department of Reproduction, Obstetrics and Herd Health, Faculty of Veterinary Medicine, Ghent University, Merelbeke, \\ Belgium. \\ ${ }^{2}$ Academic Unit of Reproductive and Developmental Medicine, Department of Oncology \& Metabolism, Sheffield, United \\ Kingdom. \\ ${ }^{3}$ Institute of Biomedicine and Translational Medicine, Department of Pathophysiology, University of Tartu, Tartu, Estonia.
}

\begin{abstract}
Scientific societies have a major role in facilitating and disseminating scientific discoveries. Here, we are all members of societies related to reproductive biology, such as AETE (European Association of Embryo Transfer), SRF (Society for Reproduction and Fertility) or ESHRE (European Society of Human Reproduction and Embryology). However, many of you may be unfamiliar with COST Actions. These are atypical, EU-funded temporary societies, that can have a huge impact upon the lives and careers of their members. The objective of the present paper was to capture the influence that one specific COST Action, EPICONCEPT, and to a lesser extent also the earlier COST Action GEMINI, has had on European scientists involved in animal reproduction and embryo transfer. We discuss the intrinsic value of belonging to EPICONCEPT, we focus on how EPICONCEPT advanced the careers of the scientists involved and the lessons learned. We conclude that such specific short-lived societies as granted by COST can be the basis of permanent collaborative ties and networking within Europe. Moreover, EPICONCEPT has been a very useful tool to raise awareness about epigenetics among animal scientists and breeders.
\end{abstract}

Keywords: COST, epigenetics, periconception environment, researcher.

\section{Introduction}

Young scientists are not always aware of the importance of attending different conferences and the value of engaging in networking activities. $\mathrm{My}^{1}$ former boss told me: "If you attend a conference it will benefit your network". But do we actually need a network to be successful in science and to advance in our career? I can now wholeheartedly say: "Yes" to this question.

The network that was of major importance to me, and also to many other European researchers, was EPICONCEPT, short for "Epigenetics and

\footnotetext{
${ }^{1}$ Just for the reader's information, wherever in this manuscript the words "I/me/my" are used, it refers to my own (Ann Van Soom) experiences. However, whenever "we" is used it will refer to my coauthor and/or the wider COST community.
}

Periconception Environment".

EPICONCEPT really started about ten years ago. I received an e-mail from a scientist, Prof Alireza Fazeli, that was at that time only affiliated to the University of Sheffield in the UK. It read: "Dear Dr. Van Soom, we may have never met before, but I know from your published work that you are interested in sperm-oviduct interaction. I plan to apply for a COST Action that is focusing on this broader topic. Are you willing to take part in this Action and if so, can you give me the names of other people who may also intend to join? If you are interested, we can also talk on the phone, so I can explain the background."

I had never heard of a COST Action before, so I agreed to talk on the phone to learn more. I asked Alireza if this was a way to raise European money for research. "No", he said, "you can get money for organizing conferences and workshops, for visiting each other's laboratories and for exchanging PhD students."

At first, I did not really think that the COST Action was going to be a useful approach at all, but I agreed to contribute nonetheless. I produced a list of emails from people involved in research regarding oviducts and spermatozoa, and thought that would be the last thing that I would ever hear from it. Little did I know! Alireza Fazeli, together with many others, turned from an unknown person into a dear lifelong friend. I will review in this personal testimony, how EPICONCEPT affected our lives and careers, and we will point out what we have learned from EPICONCEPT.

\section{History of COST Action}

The COST-Action website (http://www.cost.eu/), states "COST is a unique means for European researchers, engineers and scholars to jointly develop their own ideas and new initiatives across all fields of science and technology through trans-European networking of nationally funded research activities."

The first COST Action I was involved in was GEMINI (Maternal Interaction with Gamete and Embryo 2008-2012). Until then, I had been mainly involved with bovine embryos and how they interact with their environment (the Petri dish), but during this action, we learned about maternal interaction in insects, fish, reptiles (Holt and Lloyd, 2010) and even apprehended information on in silico models (Burkitt et 
al., 2011). I started writing (opinion) papers with other European scientists, we exchanged students with other labs, we organized workshops and meetings and we were inspired by all these contacts and communications: it broadened our view, it encouraged us to apply for more nationally funded projects and we were able to start common research with other EU-groups, with our own funding of course. The annual meetings and workshops increased the bonds we had and they created the sense of belonging to a large scientific family.

COST Actions can be a very useful tool, and we used it very well: GEMINI turned out to be important for my career and also for many young investigators and their supervisors. Scientific societies, including COST Actions, have a major role in facilitating scientific discoveries and disseminating them (Bahr, 2008). To use a metaphor: The network that is created by a COST Action is like a spider web, connecting different people with sticky threads, and when a new fly is caught, it is signaling by its movement its presence to the central spider, who can easily catch it for a presentation at one of the upcoming conferences. The outstanding feature of COST is that it provides a platform to young investigators, to researchers that are underrepresented (many of whom are female), to researchers from countries within and outside Europe that is very different from the "Old Boy Network" (see Merriam Webster: an informal system in which wealthy men with the same social and educational background help each other), which is not always in favor of young researchers belonging to a minority to present his or her research.

In this digital age, one could wonder if the network that is provided by COST and other societies could not be replaced by a Facebook page, or by twitter, or by a comparable social media connection. The answer is probably "No". A questionnaire which was filled in by trainee members of the Society for Study of Reproduction provided indeed more evidence that people need to interact in a personal way, to connect and to stay current (Table 1). Meeting in an informal manner removes many of the prejudices people may have when they receive an unsolicited e-mail from somebody they have not met before. Contrary to the common expectation, a discussion at a poster session or even having a drink at the bar with another scientist can be the start of a lifelong scientific collaboration!

So we can conclude that COST Actions are indeed useful, contrary to what I expected after my first contact with Alireza Fazeli. During this period, my career moved on to the fast track. I applied for many more grants than before and as a result, I was also successful in achieving more funding. At the end of GEMINI, I even decided to apply for a second COST action, EPICONCEPT, as the Chair this time. The topic was on epigenetics, and although I was not a molecular biologist, I had always been intrigued by genetics, by evolution, by Lamarck and Darwin, and the link it had with embryology, as in the discredited theory of Ernest Haeckel, where he stated that ontogeny is a recapitulation of phylogeny. EPICONCEPT would give me the opportunity to delve deeper into this topic. I considered the fact that I was not a geneticist to be an advantage, since I had to make the topic understandable for non-geneticists. This is often the key to success: convey your message in a simple, understandable way, both to other scientists and to the general public. That too, I learned during the COST Actions.

Table 1. Survey filled in by trainees that were member of Society for the study of Reproduction (SSR) (adapted from Bahr 2008)

\begin{tabular}{lll}
\hline Question & Most popular answer & Second important answer \\
\hline $\begin{array}{l}\text { What is the primary reason for } \\
\text { joining a scientific society? }\end{array}$ & To attend annual meeting & $\begin{array}{l}\text { To share knowledge with other } \\
\text { researchers }\end{array}$ \\
\hline $\begin{array}{l}\text { What is the value of belonging to a } \\
\text { scientific society? }\end{array}$ & $\begin{array}{l}\text { To interact with people who share } \\
\text { common interest and to meet } \\
\text { experts in the field }\end{array}$ & $\begin{array}{l}\text { To stay informed about the latest } \\
\text { advances in the field }\end{array}$ \\
\hline $\begin{array}{l}\text { What can scientific societies do to } \\
\begin{array}{l}\text { advance trainees } \\
\text { scientific careers? }\end{array}\end{array}$ & $\begin{array}{l}\text { To facilitate networking and } \\
\text { collaboration }\end{array}$ & To hold annual meetings \\
\hline
\end{tabular}

\section{Why is epigenetics interesting when you are working with embryos?}

So why did I think EPICONCEPT was an interesting line of research? Many things had evolved in the field of assisted reproduction since the birth of the first test-tube baby, Louise Brown, in 1978. Cattle were the first species, after the human, in which transfers of in vitro produced embryos were performed on a large scale during the 1990s. Coinciding with the first reports of the birth of the first cloned calves and sheep, troubling anecdotal reports emerged of congenital abnormalities associated with cloned animals and later in a broader perspective, also of abnormal offspring born after in vitro culture of ruminant embryos
(Willadsen et al., 1991; Van Soom et al., 1994; Walker et al., 1996). The most obvious characteristic of the abnormal offspring was an overgrowth phenotype, and thus the syndrome was termed "Large Offspring Syndrome" or "Abnormal Offspring Syndrome" (for review see Farin et al., 2010).

As early as 1998 it was hypothesized that the mechanism was probably related to changes in DNAmethylation of imprinted genes, which were imposed upon the embryo by its exposure during a critical period to a perturbing environment (Young et al., 1998).

Also in humans there were similar reports on the influence of the intrauterine or perinatal environment on fetal development. Barker postulated that a baby with a low birth weight has a higher risk to 
suffer from cardiovascular disease as an adult (Barker $e t$ al., 1989). This hypothesis was later called the "Developmental Origins of Health and Disease" or DOHAD hypothesis, and by the mid-1990s the concept that late-onset diseases are related with earlier prenatal events, was well established (Barker, 1995; Grace and Sinclair, 2009). Barker studied mainly fetal undergrowth, but also fetal overgrowth has been reported in humans. Assisted reproduction, which is currently accounting for $5-6 \%$ of the live birth rates in Belgium, has indeed been associated with increased risk of imprinting diseases such as Beckwith-Wiedemann syndrome, which is a fetal overgrowth syndrome (Owen and Segars, 2009). Both "Large Offspring Syndrome" in cattle and the "Developmental Origins Of Adult Health And Disease" hypothesis in humans are reflections of the fact that small changes in the environment to which the embryo is exposed can either lead to obvious phenotypical changes in the neonate (oversized calf, Beckwith-Wiedemann baby) or to more subtle, long-term programming effects, which can lead to impaired health during adulthood (Sinclair and Singh, 2007; Fig. 1).

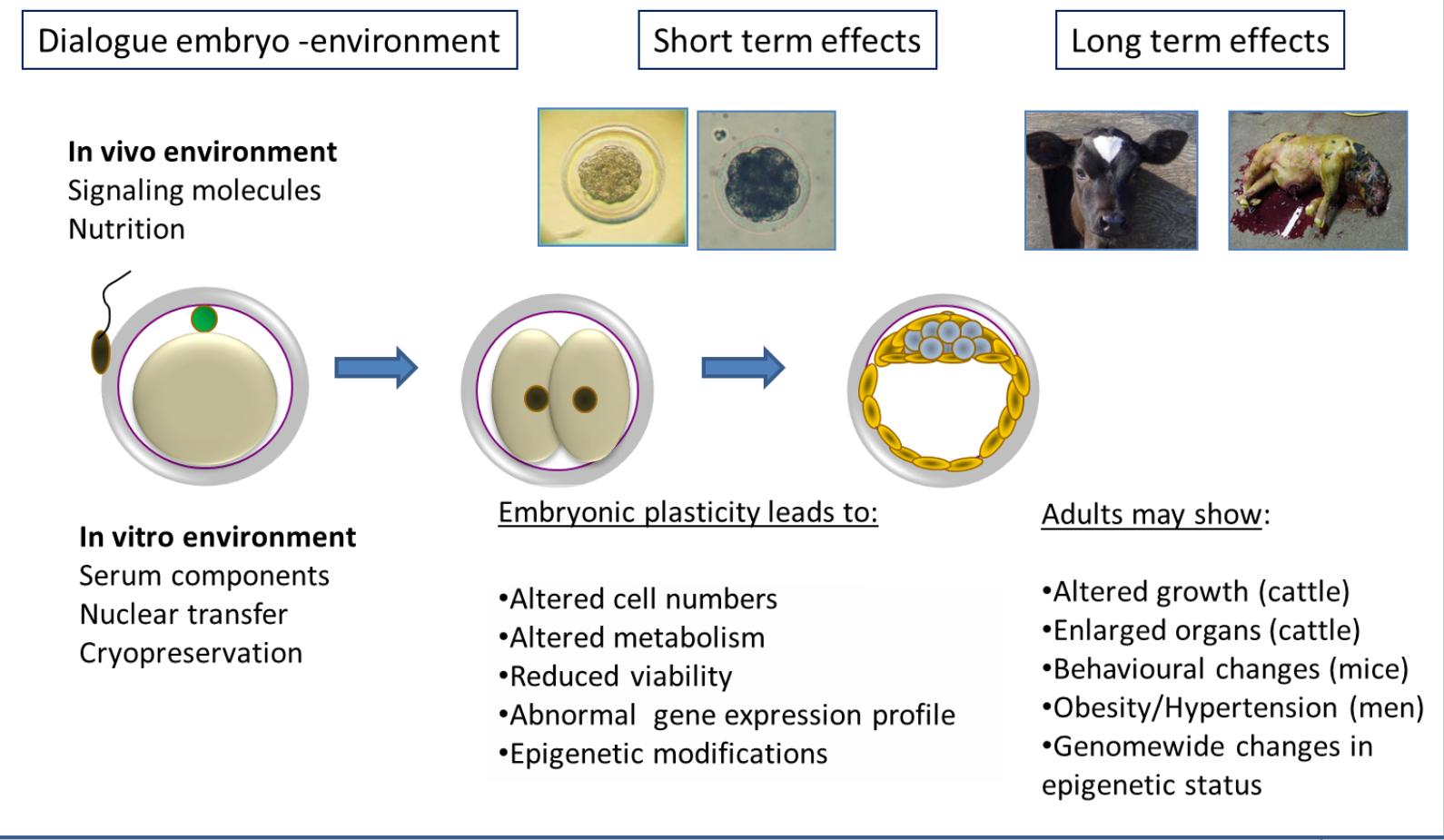

Figure 1. An unusual environment to which the embryo is exposed will lead to short and long term effects, both of which are caused by epigenetic modifications and which in some cases can be transgenerational. At present, these effects have been shown to be induced by in vitro embryo culture in mice, man and cattle.

Such an important concept (DOHAD) called for more in depth research. The field of environmental epigenetics, which was closely related to the concept of Developmental Origins Of Health And Disease, was studied extensively by using various animal models. These models provided a means to understand how environmental factors, which are present at periconception, may induce heritable changes in gene expression and as such, can cause diseases that cannot be explained by conventional genetic mechanisms (Rosenfeld, 2010). These changes were called epigenetic changes: in Epiconcept, we aimed to apply our animal models to the search for an answer on how environment affects offspring health and performance in the adulthood (Van Soom et al., 2010, 2013, 2014). Understanding the epigenetic mechanisms involved in embryonic development will help to address such issues as a) the risks associated with stress, illness or dietary restrictions and metabolic imbalances during the periconceptional period, which is including prenatal and early postnatal life (Mossa et al., 2013; Fleming et al.,
2015; Velazquez, 2015); b) the effects of maternal and paternal nutritional status/stress on epigenetic programming through the germline; and c) transgenerational effects where, in future, greater emphasis in livestock species should be placed on traits of agricultural importance (Gonzalez-Recio et al., 2012; Opsomer et al., 2017).

Epigenetic changes may be less harmful than genetic mutations since they are reversible. Understanding the healthy settings of the periconception environment that avoid deleterious epigenetic changes will allow to potentially improve this environment to attain the ideal conditions to which breeding animals and embryos should be exposed in order to prevent epigenetic mutations to occur. The periconception environment encompasses ontogenesis and the organs and tissues in which gametogenesis, embryogenesis, implantation and placentation take place. Although sexual reproduction is globally robust, it is also a vulnerable process. Gametes and embryos are especially vulnerable to epigenetic changes. Most epigenetic marks are systematically 
erased in the preimplantation embryo and in the primordial germ cells in order to down-regulate the inheritance of epigenetic (acquired) information between generations, and appear again later on. Likewise, epigenetic processes are responsible for laying down the gender-specific imprinting that allows for gender-specific gene expression, which is of paramount importance for embryonic development and placentation.

\section{What have we learnt during EPICONCEPT}

Parental stress before, during and after conception (i.e. the periconception period), induces epigenetic changes in gametes and embryos. Such epigenetic changes may adversely affect the future health, development, productivity and fertility of those offspring. While there is increasing evidence for this in agricultural species, most of this knowledge is derived from epidemiological studies in humans and controlled studies in laboratory animals. In EPICONCEPT, time frames and mechanisms during which the gametes and early embryo are susceptible to epigenetic modifications were investigated in livestock in order to optimize their health and productivity. The objectives were to:

1. Develop an epigenomic toolbox for large scale screening of epigenetic changes in gametes and embryos.

2. Define the factors that can influence the epigenetic profile during the periconceptional period of gametes and embryos.

3. Define the time-window during which most epigenetic changes take place

4. Define the range of the optimal periconception environments to ensure healthy offspring.

5. Compare the susceptibility of different species (livestock, poultry, fish) and different model systems (in vivo vs. in vitro) to epigenetic disturbances.

We achieved these objectives by discussing these topics at our conferences and workshops. Here, we need to acknowledge the generosity of fellow scientists who were not members of Epiconcept, but who travelled from around the world to participate in our meetings, to share their knowledge with us and whose presence meant that we were exposed to cutting edge science and methodologies. As material output we published several review papers on the topic (Brevini et al., 2014; Gutierrez-Adan et al., 2014; O'Doherty and McGettigan, 2014; Salvaing et al., 2014; Anckaert and Fair, 2015), in a Research Front entitled Epigenetics and Periconception environment in Reproduction, Fertility and Development (Editors: Ann Van Soom and Alireza Fazeli), and a book entitled Periconception in Physiology and Medicine (Editors: Alireza Fazeli and William V. Holt), which is in press by Springer.

Public engagement activities were carried out during the COST Action to inform the general public on the importance of the epigenome via the periconception environment in future food production, health and welfare. We communicated via organized Weeks and
Nights of Science at our universities, we raised awareness and had an impact on young students even at the level of the secondary school pupils. We used our website (cost-epiconcept.eu) to inform scientists and the public and we produced a facebook page (www.facebook.com/Epiconcept-COST-Action$1381626895453232 /$ ? fref $=$ ts ) to interact with scientists, stakeholders, clinicians and practitioners to improve gamete and embryo handling and animal husbandry and breeding. We informed different companies and invited them to our workshops and courses, to learn about the possible impact of gamete and embryo handling on later life. A major success story from our action was to convince stakeholders, such as companies involved in semen freezing and cattle breeding by artificial insemination, to become involved in new research EUprojects on this topic.

\section{Final conclusions}

With this short review I wanted mainly to point out how important interaction is between scientists. We have not only got to know each other better during Epiconcept, we have also become like friends and family. Some of us are still collaborating, either in an EU Project, or in a project based on national funding or as a member of a new Cost Action, Cell-fit (https://www.facebook.com/COST-Action-16119-

CellFit-1660173010901682/ ). I do not have a final message for you, suggesting to do this or that to prevent epigenetic changes to occur, in order to prevent diseased offspring resulting from your research. But I do think that we have raised awareness, that scientists now know that the addition of certain ingredients, such as serum, to the culture medium can have far reaching consequences, and that the introduction of novel techniques should be carefully investigated for subsequent epigenetic effects. But since epigenetics is part of life, and since we are all influenced by our environment; it is also important to realize that we cannot prevent this interaction with the environment. We should live healthy lives and we need to expose our gametes and embryos to a healthy environment, but we should not be terrified or reluctant towards change.

\section{Acknowledgments}

COST - office is acknowledged for creating this excellent tool to interact between scientists and laboratories. We also wish to thank Dr. Laszlo Tecsi for his invaluable services to the members of the Epiconcept Cost Action.

\section{References}

Anckaert E, Fair T. 2015. DNA methylation reprogramming during oogenesis and interference by reproductive technologies: studies in mouse and bovine models. Reprod Fertil Dev, 27:739-754.

Bahr JM. 2008. Are scientific societies serving the need of graduate and postdoctoral students? Reprod Fertil Dev, 20:19-22. 
Barker DJ, Winter PD, Osmond C, Margetts B, Simmonds SJ. 1989. Weight in infancy and death from ischaemic heart disease. Lancet, 2:577-580.

Barker DJ. 1995. Fetal origins of coronary heart disease. Br Med J, 311:171-174.

Brevini T A L, Pennarossa G, Maffei S, Gandolfi F 2015. Phenotype switching through epigenetic conversion. Reprod Fertil Dev, 27:776-783.

Burkitt M, Walker D, Romano DM, Fazeli A. 2011. Computational modelling of maternal interactions with spermatozoa: potentials and prospects. Reprod Fertil Dev, 23:976-989.

Farin CE, Farmer WT, Farin PW. 2010. Pregnancy recognition and abnormal offspring syndrome in cattle. Reprod Fertil Dev, 22:75-87.

Fleming TP, Watkins AJ, Sun C, Velazquez MA, Smyth NR, Eckert JJ. 2015. Do little embryos make big decisions? How maternal dietary protein restriction can permanently change an embryo's potential, affecting adult health. Reprod Fertil Dev, 27:684-692.

González-Recio O, Ugarte E, Bach A. 2012. Transgenerational effect of maternal lactation during pregnancy: a Holstein cow model. PLoS One, 7:e51816. Grace KS, Sinclair KD. 2009. Assisted reproductive technology, epigenetics, and long-term health: a developmental time bomb still ticking. Semin Reprod Med, 27:409-416.

Gutierrez-Adan A, White CR, Van Soom A, Mann MRW. 2014. Why we should not select the faster embryo: lessons from mice and cattle. Reprod Fertil Dev, 27:765-775.

Holt WV, Lloyd RE. 2010. Sperm storage in the vertebrate female reproductive tract: how does it work so well? Theriogenology, 73:713-722.

Mossa F, Carter F, Walsh SW, Kenny DA, Smith GW, Ireland JL, Hildebrandt TB, Lonergan P, Ireland JJ, Evans AC. 2013. Maternal undernutrition in cows impairs ovarian and cardiovascular systems in their offspring. Biol Reprod, 88:92. doi: 10.1095/biolreprod.

O'Doherty AM, McGettigan P. 2014. Epigenetic processes in the male germline. Reprod Fertil Dev, 27:725-738.

Opsomer G, Van Eetvelde M, Kamal M, Van Soom A. 2016. Epidemiological evidence for metabolic programming in dairy cattle. Reprod Fertil Dev, 29:52-57.
Owen CM, Segars JH Jr. 2009. Imprinting disorders and assisted reproductive technology. Semin Reprod Med, 27:417-428.

Rosenfeld CS. 2010. Animal models to study environmental epigenetics. Biol Reprod, 82:473-488.

Salvaing J., Li Y., Beaujean N., O'Neill C. 2014. Determinants of valid measurements of global changes in 5 -methylcytosine and 5 -hydroxymethylcytosine by immunolocalisation in the early embryo. Reprod Fertil Dev, 27:755-764.

Sinclair KD, Singh R. 2007. Modelling the developmental origins of health and disease in the early embryo. Theriogenology, 67:43-53.

Van Soom A, Mijten P, Van Vlaenderen I, Van den Branden J, Mahmoudzadeh AR, de Kruif A. 1994 Birth of double-muscled Belgian Blue calves after transfer of in vitro produced embryos into dairy cattle. Theriogenology, 41:855-867.

Van Soom A, Vandaele L, Peelman LJ, Goossens K, Fazeli A. 2010. Modeling the interaction of gametes and embryos with the maternal genital tract: from in vivo to in silico. Theriogenology, 73:828-837.

Van Soom A, Vandaele L, Goossens K, Heras S, Wydooghe E, Kamal MM, Van Eetvelde M, Opsomer G, Peelman L. 2013. Epigenetics and the periconception environment in ruminants. Proc Belg Royal Acad Med, 2:1-23.

Van Soom A, Peelman L, Holt WV, Fazeli A. 2014. An introduction to epigenetics as the link between genotype and environment: a personal view. Reprod Domest Anim, 49(suppl. 3):2-10.

Velazquez MA. 2015. Impact of maternal malnutrition during the periconceptional period on mammalian preimplantation embryo development. Domest Anim Endocrinol, 51:27-45.

Walker S.K, Hartwich KM, Seamark R. 1996. The production of unusually large offspring following embryo manipulation: concepts and challenges. Theriogenology, 45:111-120.

Willadsen SM, Janzen RE, McAlister RJ, Shea BF, Hamilton G, McDermand D. 1991. The viability of late morulae and blastocysts produced by nuclear transplantation in cattle. Theriogenology ,35:161-170.

Young LE, Sinclair KD, Wilmut I. 1998. Large offspring syndrome in cattle and sheep. Rev Reprod, 3:155-163 